\title{
The Insulating Effects of Rice Husks Addition on the Mechanical Properties of Clay Samples from Kaduna State Nigeria
}

\author{
Manukaji John U. \\ Federal Polyrechnic, Bida Niger State Nigeria
}

\begin{abstract}
Insulating refractories are a special class of refractories produced to have a highly porous structure with air entrapped therein. The presence of air in these pores reduces the conductive capacity of the refractories and therefore increasing their insulating characteristics. Apart from the natural occurring fire clays which has been adjudged an insulating refractories, other clays can have their insulating characteristics improved by the addition of materials like saw dust, rice husks and other farm wastes. An investigation was therefore carried out to ascertain the effects of rice husks addition on clay samples from Kaduna State as refractory insulating materials for industrial use. The results on linear shrinkage, thermal conductivity, apparent porosity and solid density of all the samples, showed that the linear shrinkage averaged $8.7 \%$ with $0 \%$ rice husks and $8.4 \%$ with $40 \%$ addition of rice husks, bringing them closer to the lower range of the international standard of $7-10 \%$. Apparent porosity averaged $13 \%$ with $0 \%$ rice husks and $17 \%$ with $40 \%$ addition of rice husks bringing them closer to the acceptable range of $20-80 \%$. Solid density averaged $2.9 \mathrm{~g} / \mathrm{cm}^{3}$ with $0 \%$ rice husks and $2.6 \mathrm{~g} / \mathrm{cm}^{3}$ with $40 \%$ rice husks, still bringing them closer to the international range of $2.3-3.5 \mathrm{~g} / \mathrm{cm}^{3}$ while thermal conductivity was $0.515 \mathrm{~W} / \mathrm{mk}$ with $0 \%$ rice husks and $0.142 \mathrm{~W} / \mathrm{mk}$ with $40 \%$ rice husks thereby improving their insulating properties.
\end{abstract}

Key Words: Insulating, effects, rice husks, clay, kaduna State

\section{INTRODUCTION}

An insulator is generally referred to as any material that impedes, obstructs or offers a very high resistance to the flow of the target fluid. The fluids of concern in this case are electricity and heat. Therefore an insulator is any material that offers a very high resistance to the flow of heat and current. Manukaji .(2004) Insulating refractories are high porosity refractories having low thermal conductivity and high thermal insulation properties suitable for minimizing heat losses and maximizing heat conservation in furnaces. They derive their low thermal conductivity from their pores, while their heat capacity is determined almost entirely by the solid component. Olusola (1998) The insulating effect is principally the result of achieving a series of air spaces between an alternate series of solid boundaries.

One of the most widely used materials is diatomite, also known as kieselguhr, which is made up of a mass of skeletons of minute aquatic plants-deposited thousands of years ago on the beds of seas and lakes. Chemically this consists essentially of silica contaminated by clay and organic matter. Among the larger deposits are those of Denmark, Germany, Portugal etcAbifarin (1999)

The heat resistant insulating materials for this kind of duty range from baked clay, silica, mica and slug, which is a by-product of iron and steel extraction from raw materials. The important factors to be considered in the formulation of these heat resistant insulating materials are

(1) To ensure that no metallic electricity conductors such as ferrous or ferric materials are contained therein

(2) That material strength of the heat dissipating material is enough to sustain the conductor and indeed other weights of materials it is expected to support.

(3) To ensure that under high heat condition $500-2000^{\circ} \mathrm{C}$ the dielectric strength of the heat dissipating material is stable so as to prevent current leakage.

(4) The heat dissipating material should not char, burn or loose its chemical composition under high heat condition.

If high heat resistance materials

(1) do not crack at very high temperature

(2) possess high insulation resistance

(3) are non absorbent (or kept out of deteriorating moisture or degrading chemicals)

(4) are of required material strength

(5) can dissipate absorbed heat homogeneously

(6) do not deteriorate the quality of the heat source, then it qualifies to be used as a heat dissipating insulating material IEE (1992). 
The production of insulating base plates from clay base materials are carried out by a number of different methods. These have been summarized as follows:

(i) Incorporation of natural or synthetic lightweight materials, such as diatomite, expanded vermiculite, or raw kyanite

(ii) Inclusion of materials which are later removed by combustion or sublimation, more usually the former.

(iii) Production of a cellular structure by mechanical beating using a frothing agent.

(iv) Formation of gas bubbles in a semi-fluid medium by chemical reaction

(v) Miscellaneous methods.

Although certain of the above processes would seem comparatively simple, the bulk production of porous clay insulating base plates of low conductivity is, in fact, a difficult operation that is frequently associated with considerable losses both of the base plates and money BSI (1975). Of the above methods, the use of combustibles is probably the earliest and the most widely employed. The particular material used is partly a function of the water required in the product and partly of availability. Sawdust and rice husks are perhaps the most common material, though better results are said to be obtained with such exotic materials as polystyrene expanded beads. Even simple materials like sawdust and rice husks require careful selection and control, since such factors as the grain size and swelling tendency in contact with water may have a marked effect both on the ease of manufacture and the properties of the product. Manukaji (2004)

For a refractory clay to have good insulating characteristics, it must have amongst others the following characteristics

(1) It must be highly porous

(2) It must have low thermal conductivity

(3) It must have low solid density

(4) It must have a reasonably low linear shrinkage.

In this experiment therefore, the effects of rice husks addition on the above properties of the clay specimens were studied and the results are shown in the graphs below Further more, statistical analysis was used to study each clay sample closely, with reference to linear shrinkage, apparent porosity, bulk density and thermal conductivity. Analysis of variance, regression analysis and correlation coefficients analysis were modeled for each clay specimen and the results were shown below.

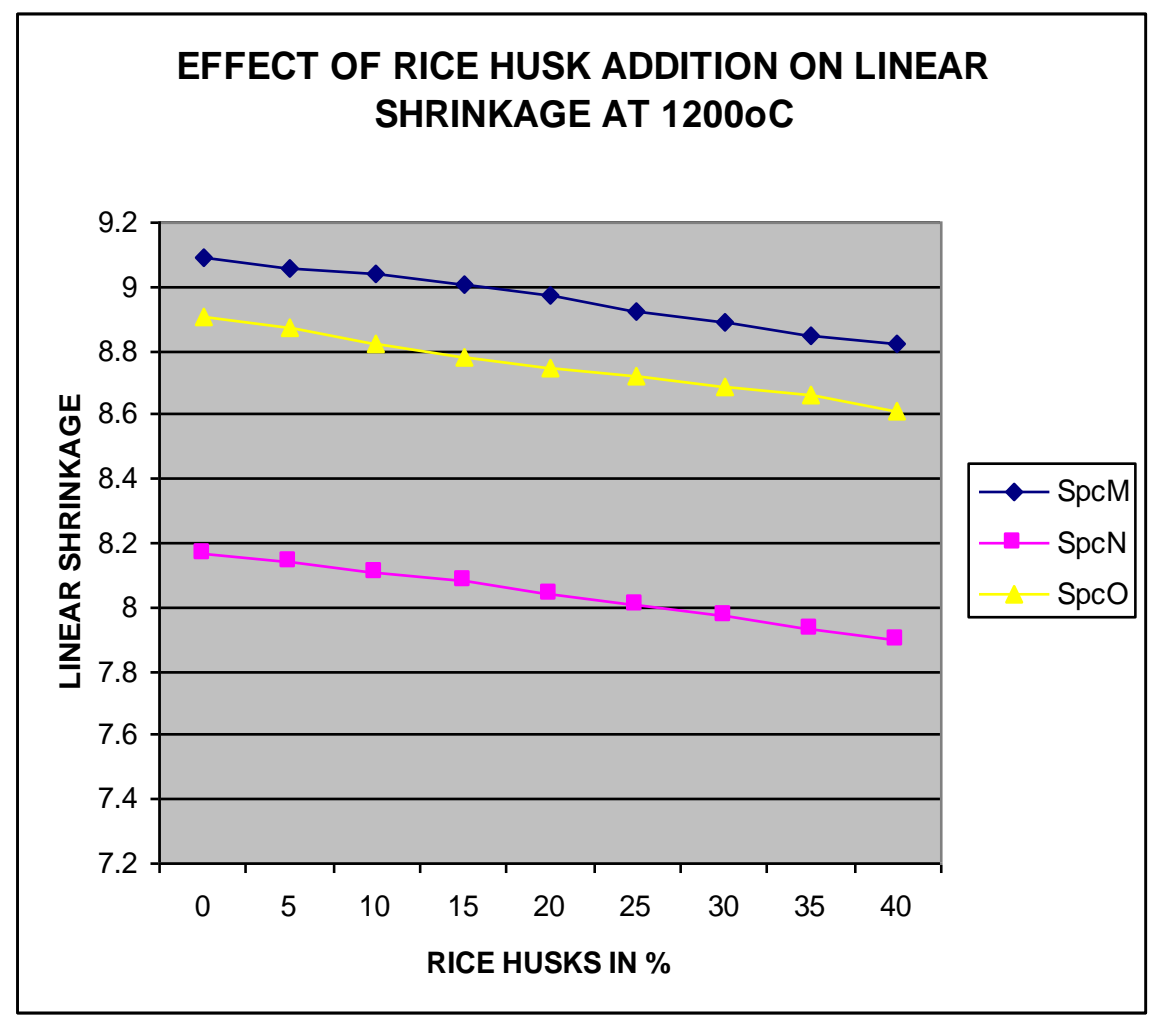



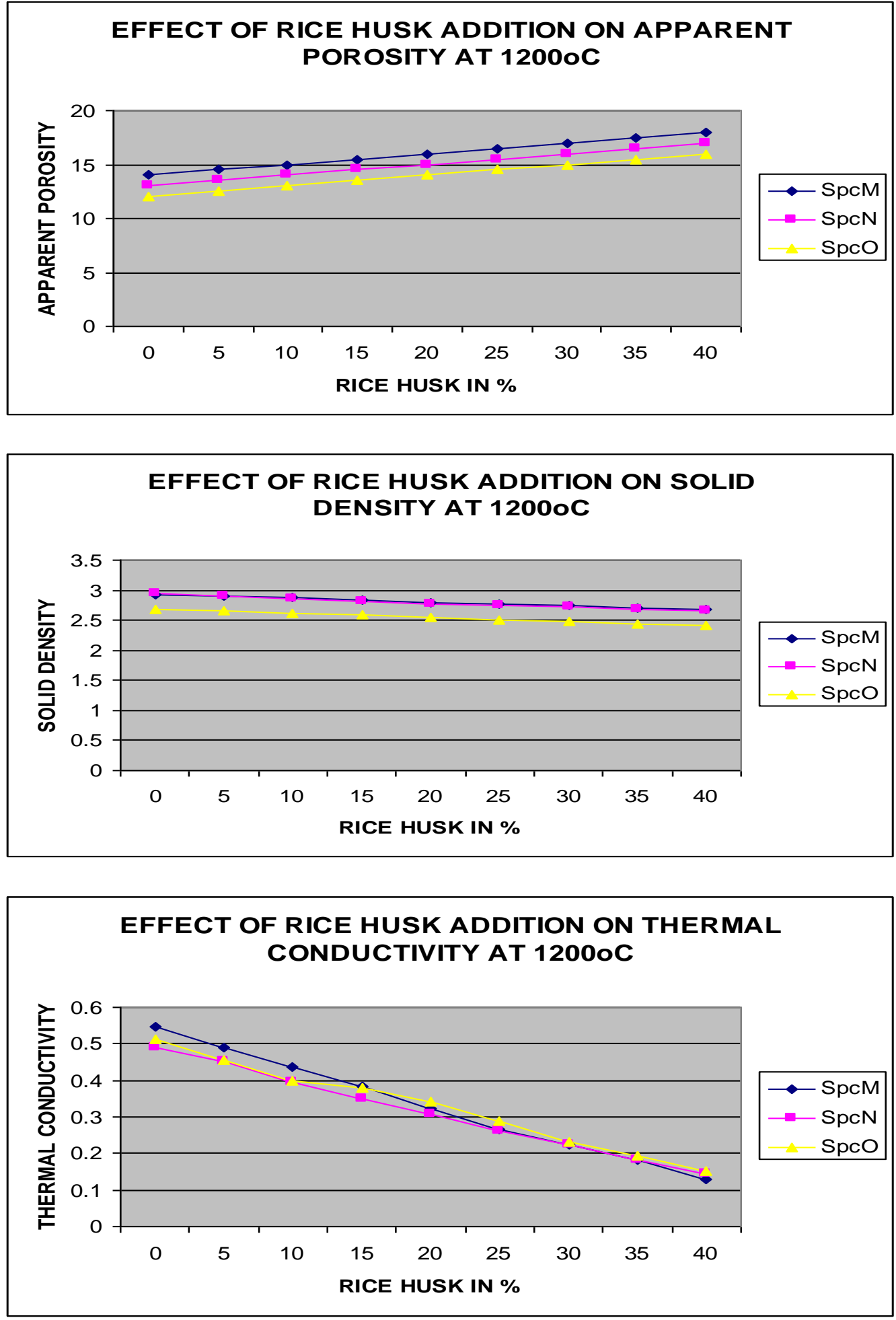

II. RESULTS AND DISCUSSION

The effects of rice husks addition on the above properties of the clay specimens were studied and the results are shown and discussed as follows.

1. The linear shrinkage showed a steady reduction in value from $8.7-8.4 \%$ as the quantity of rice husks addition increased thereby bringing the values closer to the lower values of the acceptable range of $7-10 \%$ Ijagbemi(2002).

2. The solid density of the samples reduced steadily from $2.9-2.6 \mathrm{~g} / \mathrm{cm}^{3}$ as the rice husks addition increased moving them closer to the lower acceptable range of $2.3-3.5 \mathrm{~g} / \mathrm{cm}^{3}$ Ijagbemi (2002) 
3. The apparent porosity increased in value from $13-17 \%$ in most of the samples thereby bringing them closer to the international range of $20-80 \%$, Oaikhinan (1988).

4. The thermal conductivity of the samples decreased steadily from $0.515-0.142 \mathrm{~W} / \mathrm{m}^{\circ} \mathrm{k}$ as more rice husks were added making the samples better insulators Manukaji(2004)

\section{CONCLUSION AND RECOMMENDATION CONCLUSION}

(1) From the tests carried out on the addition of rice husks to the clay samples, it could be concluded that properties like porosity, thermal conductivity, linear shrinkage and solid density of the clays from these locations improved significantly and can be varied to suit the particular insulating property desired.

\section{RECOMMENDATIONS FOR FURTHER WORK}

With the studies carried out, and the analysis done of the accruing results, the following recommendations for further studies and analysis is hereby proposed.

(1) Further studies on the insulating properties of the clay samples could be carried out by analyzing the effects of the addition of saw dust, ash and other farm wastes on the clay samples.

(2) An investigation should also be carried out on the effects of the addition of bentonite on the clay samples.

(3) A study should also be carried out on how the addition of graphite, coal and asbestors would reduce the linear shrinkage properties of the clay.

(4) Efforts should also be made to reduce the ferrous and ferric content of the samples thereby reducing their thermal conductivity.

(5) Slag from iron extraction should be added to the samples to improve their insulating properties.

(6) Investigation should be made on the effects of the addition of foam-ceramic-fibres on the insulating properties of the samples.

\section{REFERENCES}

[1] Agha O A (1998) Testing of local refractory clay for producing furnace lining bricks. M. Eng. Thesis: Mech. Eng. Dept. F.U.T. Minna

[2] Akinbode F O. (1996). An investigation on the properties of termite hill as refractory material for furnace lining: Indian Foundry Journal. Pp 11-13

[3] Abifarin M. S. (1999) Investigation on local refractory materials for high temperature applications, $\mathrm{PhD}$ Thesis mech. eng. dept. Federal University Of Technology, Minna

[4] Brady N.C. and Ray R.W. (1999). The Nature properties of soil, $20^{\text {th }}$ Edition and Pub Prentice-Hall Inc. New Jersey

[5] British Standard Institution, BS1377, (1975) Methods of test for soils for civil engineering purposes. BSI, London

[6] Hans T. (1994) Industrial Minerals and rocks, $6^{\text {th }}$ Edition, Pergamon Press, Oxford.

[7] IEE (1992) Wiring regulation requirement for electrical installation BS7671, 15th Edition, A Mclay and co. Ltd Cardiff

[8] Ijagbemi C.O.(2002) Development and performance evaluation of a biomass clay lined cookstove. Meng thesis , Department of mechanical Federal University of Technology Akure, Nigeria.

[9] Li Zaigeng and Zhou Ningsheng (2001) Technological advancement in the preparation and application of monolithic refractories. China's refractories Volume 10 number 1

[10] Mohammed A. D. and Agbajelola D. O. (2011) Characterization of some selected clay deposits in Benue State. A paper presented at the $2^{\text {nd }}$ Biennial Engineering Conference. School of Engineering and Engineering technology, Federal University of Technology, Minna

[11] Mahmoud S., Ayman H and Mousa A (2003) Pretreatment effects on the catalytic activity of Jordanian bentonite . Journal of the clay mineral society Volume 51 number 1

[12] Manukaji J.U.(2004) An investigation into the use of local clays as a high temperature insulator for electric cookers. PhD Thesis mech. eng. dept. Federal University Of Technology, Minna

[13] Oaikhinan E.P (1988) Rheological properties of certain Nigerian clay. Proceedings of the international ceramic conference Australia.

[14] Olusola E O (1998) Investigation of Zungeru clay as refractory material for high temperature applications M. Eng. Thesis, Dept. of mech. engrg. F. U. T. Minna

[15] Obi V S (1995) Experimental analysis of clay for refractory purpose, B.Eng. Thesis, Dept. of mech. engrg. F. U. T Minna pp 34-48 